\title{
Recovery and reuse of alginate in an immobilised algae reactor
}

\author{
Olga Murujew', Rachel Whitton ${ }^{1}$, Matthew Kube², Linhua Fan², Felicity Roddick², Bruce \\ Jefferson ${ }^{1}$, Marc Pidou ${ }^{1, *}$
}

${ }^{1}$ Cranfield University, College Road, Cranfield, Bedfordshire, MK43 OAL, UK.

${ }^{2}$ RMIT University, GPO Box 2476, Melbourne 3001, Australia.

*Corresponding author: m.pidou@cranfield.ac.uk

\begin{abstract}
The use of microalgae for nutrients removal from wastewater has attracted more attention in recent years. More specifically, immobilised systems where algae cells are entrapped in beads in a matrix of a polysaccharide such as alginate have shown great potential for nutrients removal from wastewater to low levels with reduced retention times and hence smaller footprint. However, a significant operational cost in the up-scaling of alginate-immobilised algae reactors will be the gelling agent alginate. To reduce expenditure of this consumable a proof-of-concept is given for an alginate recycling method using sodium citrate as a dissolving agent. Using algae beads made from virgin and recycled alginate yielded comparable removal rates for both phosphorus and nitrogen compounds from wastewater. At lab-scale, an alginate recovery of approximately $70 \%$ can be achieved which would result in a net operational cost reduction of about $60 \%$.
\end{abstract}

Keywords: alginate, immobilised algae, phosphorus removal, recovery, recycle 


\section{Introduction}

Tertiary phosphorus $(P)$ removal with algae is a promising development because it offers efficient and combined nutrient removal of nitrogen $(N)$ and phosphorus $(P)$ compounds [1, 2]. Algae based wastewater treatment can be divided into suspended and non-suspended systems and within those categories into enclosed and open to the environment. In suspended systems the algal biomass is free flowing either in a high-rate algal pond (HRAP) or a photo-bioreactor (PBR). Implementation of suspended algae in tertiary wastewater treatment systems remains challenging due to large footprint (HRAP), algal biomass separation (both) and treatment resilience to feed water (shock loadings) and treatment conditions (light, algae contamination ...) variability (both) [3]. Switching to immobilised systems significantly reduces these issues with the algae either grown attached to a surface as a biofilm or entrapped in beads in a matrix of a polysaccharide such as alginate, carrageenan or chitosan [3, 4]. Immobilised algae systems which use artificial lights to enable effective treatment at all times are typically characterised by high algal concentrations of selected species without risk of cross contamination, leading to very short hydraulic residence times (HRT) and hence small footprints [3, 4]. To illustrate, HRAPs are typically operated at HRTs of up to 10 days; whereas immobilised algae reactors (IBR) can be operated at HRTs as low as 3 hours [5]. An advantage that all algae technologies share is the generation of algal biomass which can be utilised as a source of proteins, fertilisers or bio-energy to offset energy demand from the operation of the system [6, 7]. Accordingly, immobilised algae reactors are a promising technology not only for efficient nutrient removal but also when targeting sustainable alternatives with added value such as energy recovery. Research from lab to pilot scale has shown that effluent $P$ concentrations of $0.1 \mathrm{mg} / \mathrm{L}$ can be achieved along with ammonium $\left(\mathrm{NH}_{4}{ }^{+}\right)$levels below $0.1 \mathrm{mg} / \mathrm{L}$ and nitrate $\left(\mathrm{NO}_{3}{ }^{-}\right)$below $0.5 \mathrm{mg} / \mathrm{L}[5,8]$ as a polishing step. This demonstrates the potential of the technology in particular to meet the stricter phosphorus consent for discharge coming into place across Europe of below $0.5 \mathrm{mg} / \mathrm{L}$ and as low as $0.1 \mathrm{mg} / \mathrm{L}$. 
Successful up-scaling of the IBR technology requires the development of an optimized reactor design and provision of infrastructure and logistics to produce algae beads at commercial scale. Importantly, such an innovative technology needs to be cost-competitive when compared to conventional options but to date, no IBR operation at full-scale has been reported [5].

The key component of the IBR technology is the beads of immobilised algae which are produced when a concentrated algal suspension is homogeneously mixed in a dilute sodium alginate solution. Droplets of this mixture are then continuously added to a curing solution, calcium chloride, in which the alginate solidifies forming algae beads. The gelation of alginate, as used in the algae beads production process, is based on an ion transfer of sodium and calcium ions and is generally described by the egg-box structure [9] (Figure 1). Previous studies have shown that the algal beads work as a batch process since they need replacing every $15-30$ days, representing a significant operating cost [10]. In fact, a previous economic analysis [10] revealed that if the beads were used once and then anaerobically digested that the annual cost of beads would represent up to $85 \%$ of the total operating cost and would limit the economic attractiveness of the technology. However, the batch cycle is based on the function of the algae and not the alginate and so it is posited that the alginate could be recovered and reused to significantly reduce the operating cost profile of the technology.

Although Ca-alginate gel beads are insoluble in water, it has been known that dissolution is possible using compounds with strong attraction towards calcium ions, e.g. complexing agents like EDTA [11]. The gelation reaction was shown to be reversible by placing the beads in a sodium phosphate buffer solution at $\mathrm{pH} 7.4$ returning the alginate to its sodium form [12]. Similarly, Qin et al. [13] converted calcium alginate fibres to alginic acid and subsequently sodium alginate by using hydrochloric acid and sodium hydroxide, suggesting that the reaction may be a simple ion exchange. Although these publications demonstrate the reversibility of the gelation process and ultimately will help inform the method to be applied in the current study, the conditions in which 
the mechanisms were studied in relation to the medical field are significantly different to what can be expected in the application of the algal beads for wastewater treatment and it is then critical to understand the reactions occurring in this context with in particular the presence of algae. Wastewater related research on alginate recovery has to date focused on its recovery from granular activated sludge [14]. Therefore, a practical method for alginate recycling from immobilised algae beads is still lacking and will be presented in this work. The aim is to deliver a proof-of-concept for a practical alginate recycling method by demonstrating the potential of reusing dissolved algae beads for re-immobilisation, as well as showing uncompromised performance in wastewater treatment, and therefore contributing to an economic benefit for the up-scaling of immobilised algae reactors.

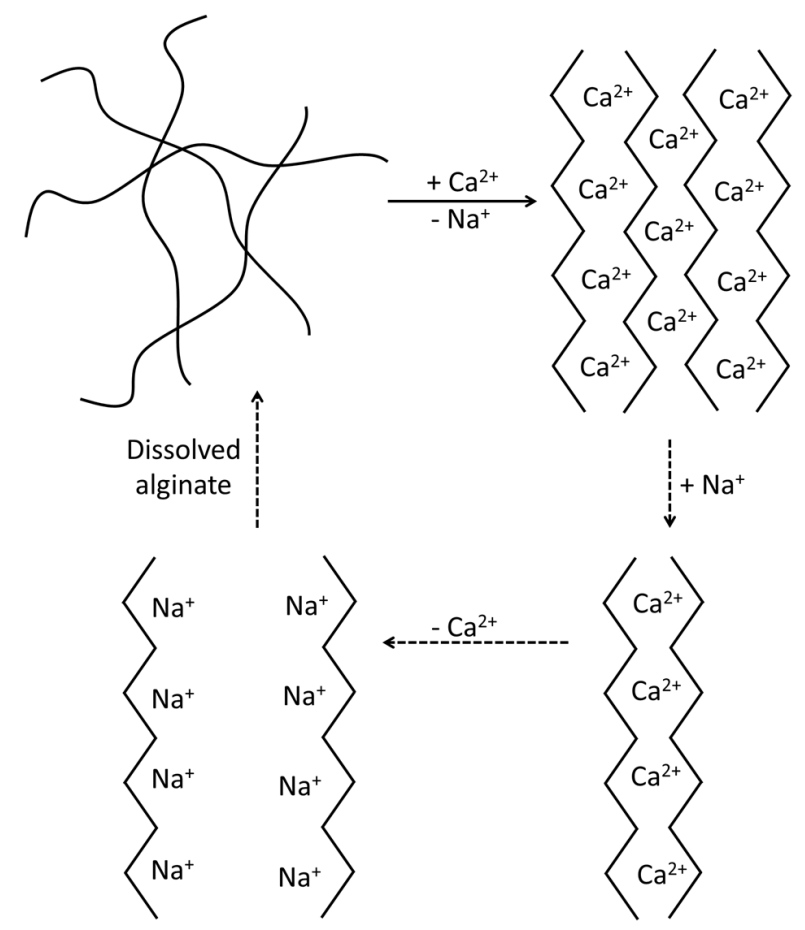

Figure 1: Egg-box model with expected ion transfer mechanism based on Ching et al. [9]. 


\section{Materials and Methods}

\subsection{Production of algae beads}

Beads were made from $2 \%(w / v)$ sodium alginate solution (Sigma-Aldrich, product number 71238 ) and $2 \%$ calcium chloride solution (Sigma-Aldrich, ACS reagent $>99 \%$, Lot MKBP4041V) following the method described by Whitton [10] using a peristaltic pump (Gilson Miniplus 3, 3mm ID tubing, $12 \mathrm{rpm}$ ) and a nozzle to generate uniform beads of about $3-4 \mathrm{~mm}$ in diameter (Figure 2). The distance of the nozzle to the solution surface was kept at $25 \mathrm{~cm}$. Beads were either made with only alginate (empty beads, EB) or alginate with algae cells (algae beads, AB) of the Scenedesmus obliquus species. After preparation, beads were stirred in $\mathrm{CaCl}_{2}$ for an additional $1 \mathrm{~h}$. Excess water was removed by drying over vacuum for $5 \mathrm{~min}$.

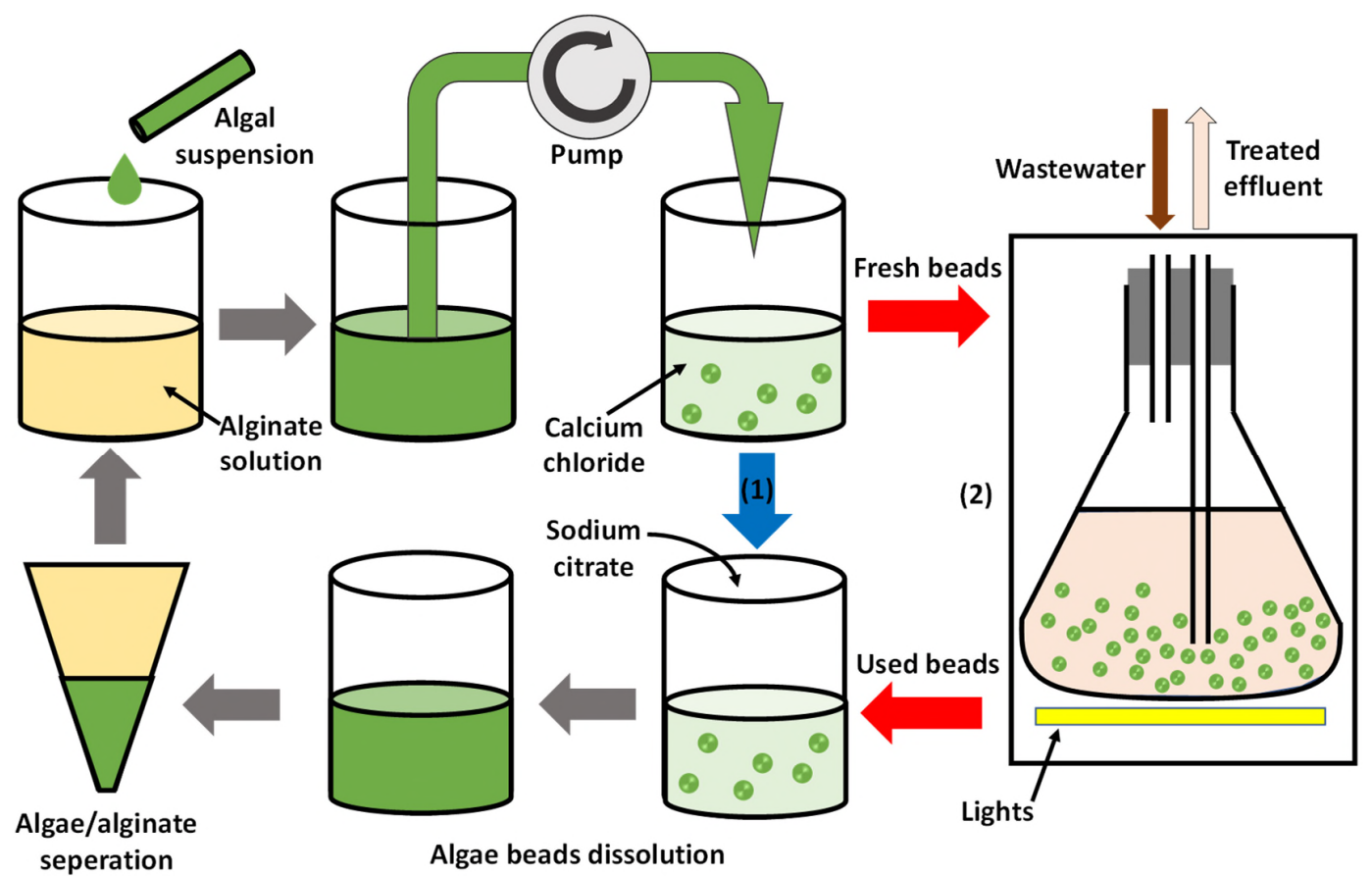

Figure 2: Process steps for algal beads production and dissolution for alginate recovery with (1) fresh and (2) used beads. 


\subsection{Alginate recovery method}

\subsubsection{Dissolution}

Preliminary tests were run to identify the most suitable chemical for bead dissolution. Three sodium salts were investigated: sodium chloride $(\mathrm{NaCl})$, sodium carbonate $\left(\mathrm{Na}_{2} \mathrm{CO}_{3}\right)$ and trisodium citrate $\left(\mathrm{Na}_{3} \mathrm{C}_{6} \mathrm{H}_{5} \mathrm{O}_{7} ; \mathrm{Na}\right.$-citrate). These salts were selected because they are readily available and cheap and/or had been previously used to dissolve calcium alginate [8]. Solutions were made up to at least $0.5 \mathrm{M}$ to have excess sodium ions. Algae beads (1 g, 61-67 beads) were added to $25 \mathrm{~mL}$ of each of the sodium solutions and magnetically stirred for 20 to $150 \mathrm{~min}$. In the subsequent experiments, beads ( $E B$ and $A B$ ) were dissolved by stirring for $1-2 \mathrm{~h}$ in $0.5 \mathrm{M} \mathrm{Na}-$ citrate solution (Merck, Batch No MC1M610493). Preliminary tests showed that a ratio of 1:2 Nacitrate:sodium alginate was suitable for dissolution of the beads. Where stated (i.e. supplemented beads), sodium alginate powder was added (equivalent to $1 \%$ weight/volume) to the recovered alginate $(\mathrm{RA})$ solutions to overcome the dilution incurred by dissolution. After dissolution of the algae beads, the algal biomass was separated with vacuum filtration with a $3 \mu \mathrm{m}$ cellulose acetate filter. However, this proved inefficient with regard to alginate yield in the filtrate. A centrifugation method, detailed below, was subsequently used for the separation of the algal biomass from the alginate for the continuous nutrient removal experiments.

\subsubsection{Re-immobilisation}

The recovered alginate was used for re-immobilisation following the previously described method for bead production. Beads made from recovered alginate were measured, counted, weighed and images obtained with scanning electron microscopy (SEM). Alginate recovery rates were then calculated based on comparison of beads produced per volume of alginate with virgin alginate (VA) and recovered alginate (RA). It should be noted that the recovery rates were calculated for beads made of recovered alginate alone, without addition of fresh alginate.

\subsubsection{Characterisation}


VA and RA were assessed for viscosity as well as the surface morphology and compressibility of the beads formed. The dynamic viscosity of alginate was measured with a rheometer (HR-3 Discovery, US) using a cone-and-plate geometry $\left(60 \mathrm{~mm}\right.$ diameter, $2^{\circ}$ cone angle, $120 \mathrm{~s}$ soak time, $25^{\circ} \mathrm{C}$ ) against an increasing shear rate from 0 to $500 / \mathrm{s}$. Detailed surface morphology of beads was investigated with a SEM (FEI Quanta 200 ESEM, FEI, USA) operated under low vacuum mode. The beads were frozen for $5 \mathrm{~h}$ at $-20^{\circ} \mathrm{C}$, then freeze-dried at $-55^{\circ} \mathrm{C}$ overnight and stored in a desiccator prior to SEM. The strength/compressibility of beads was measured with a TA-XT texture analyser (Arrow Scientific, Australia). A cylindrical probe of $3 \mathrm{~mm}$ diameter was lowered onto a bead until a resistance force of $5 \mathrm{~g}$ was detected after which the probe moved down at a speed of $0.01 \mathrm{~mm} / \mathrm{s}$, compressing the bead. Force, measured in grams, and strength, in $\mathrm{kg} / \mathrm{mm}$, was recorded against distance and time. Measurements were taken in triplicate.

\subsection{Nutrients removal in continuous operation}

The nutrient removal performance of algae beads produced with VA and RA was tested in continuously operated reactors (Algem ${ }^{\mathrm{TM}}$ Labscale Photobioreactor, Stewartby, UK). The flow rate was set to a 24-hour hydraulic retention time (HRT) and the reactors were filled with $600 \mathrm{~mL}$ wastewater and 10 beads $/ \mathrm{mL}$ [15]. Constant light was set at a photon irradiance of $200 \mu \mathrm{mol} / \mathrm{m}^{2} / \mathrm{s}$ and the temperature was controlled at $20^{\circ} \mathrm{C}$. Beads of the alga Scenedesmus obliquus, obtained from the Culture Collection for Algae and Protozoa (CCAP) (Oban,UK), were produced with a cell concentration of $10^{5}$ cells/bead. The Scenedesmus obliquus cells were first grown in suspension in $20-\mathrm{L}$ carboys with Jaworski growth medium under constant lighting at $200 \mu \mathrm{mol} / \mathrm{m}^{2} / \mathrm{s}$ and at room temperature $\left(\sim 20^{\circ} \mathrm{C}\right)$, The algal cells were harvested at the end of the exponential growth phase and concentrated by centrifugation to obtain a concentrate of about $2^{*} 10^{9} \mathrm{cells} / \mathrm{mL}$. The wastewater used was a secondary effluent from a wastewater treatment plant in Leicestershire, UK. To obtain controlled testing conditions for the trial, the wastewater was supplemented with $\mathrm{NH}_{4} \mathrm{Cl}$ and $\mathrm{KH}_{2} \mathrm{PO}_{4}$ to control the feed concentration at about $3 \mathrm{mg} \mathrm{NH}_{4}-\mathrm{N} / \mathrm{L}$ and $1 \mathrm{mg} \mathrm{P} / \mathrm{L}$, 
respectively. During the experimental runs, samples were taken every 1-2 days and analysed for $\mathrm{pH}$ (Jenway $3510 \mathrm{pH}$ meter, Staffordshire, UK) and for ortho- $\mathrm{P}, \mathrm{NH}_{4}-\mathrm{N}$ and $\mathrm{NO}_{3}-\mathrm{N}$ by colorimetric methods withtest kits (Merck, UK). Algal growth was monitored by dissolving 10 beads in $5 \mathrm{~mL}$ Na-citrate solution $(2 \% \mathrm{w} / \mathrm{v})$ and determining cell numbers using a haemocytometer and a light microscope (Olympus CX41, Essex, UK).

RA beads were made from algae beads that had treated the wastewater for 19 days. VA and RA beads were run in duplicate in parallel for a total of 17 days. Alginate recovery was performed following the previously described method. Beads from the initial trials with VA (quadruplicate) were combined (174.6 g), washed with DI water and dissolved in $150 \mathrm{~mL}$ Na-citrate solution. Algal biomass and alginate were separated by centrifugation for 15 minutes at $4000 \mathrm{rpm}$ (ThermoScientific, Sorvall Legend RT Plus, UK). The volume of the recovered alginate was 270 $\mathrm{mL}$ and $2.7 \mathrm{~g}$ of sodium alginate was added prior to addition of algal cells to produce $\mathrm{AB}$ with $\mathrm{RA}$ with a cell concentration of $10^{5}$ cells/bead. Beads (RA and VA) were then made as described previously.

\section{Results and discussion}

\subsection{Identification of a chemical for dissolution of algae beads}

Visual observation of the beads exposed to the three test dissolution solutions revealed obvious differences (Supporting information, Figure S.1). For $\mathrm{NaCl}$, no observable dissolution occurred within 150 min with slight changes in the size of the beads observed at 30 and 40 min, including a swelling of the beads after 40 minutes. In the case of $\mathrm{Na}_{2} \mathrm{CO}_{3}$, the beads started dissolving after $30 \mathrm{~min}$ and were completely dissolved after $40 \mathrm{~min}$. However, in conjunction with the dissolution process, an increase in turbidity of the solution was apparent. The formation of a precipitate is congruent with the formation of calcium carbonate due to the ion activity product of calcium 
carbonate $\left(0.09 \mathrm{~mol}^{2} / \mathrm{L}^{2}\right)$ being greater than the solubility product of $\mathrm{CaCO}_{3}\left(3.31 \times 10^{-8} \mathrm{~mol}^{2} / \mathrm{L}^{2}\right.$ [16]). In contrast, dissolution using sodium citrate was observably rapid and did not result in any formation of precipitates. The beads began to become visually smaller after $10 \mathrm{~min}$ and were fully dissolved after 20 min. During the dissolution tests, $\mathrm{pH}$ decreased from 7 to 6 when using $\mathrm{Na}$ citrate and it increased to 12 with $\mathrm{Na}_{2} \mathrm{CO}_{3}$ due to the alkaline nature of carbonate.

Considering the beads to dissolving solution ratio of $1: 25 \mathrm{w} / \mathrm{w}$ (density of the beads assumed to be $1 \mathrm{~g} / \mathrm{mL}$ as was measured to be $1.001 \pm 0.024 \mathrm{~g} / \mathrm{mL}$ ), and the respective molar ion ratios in the solutions, sodium ions were in excess of calcium ions by 106,139 and 209 times for $\mathrm{NaCl}, \mathrm{Na}_{2} \mathrm{CO}_{3}$ and $\mathrm{Na}_{3} \mathrm{C}_{6} \mathrm{H}_{5} \mathrm{O}_{7}$, respectively. However, dissolution effectiveness appeared to also depend on the charge and steric interactions of the anion component, leading to differences in the free energy of reaction, affecting the reaction of the anion with calcium. For instance, citrate, carbonate and chloride anions have ionic charges of $-3,-2$ and -1 , respectively, which suggests that the high charge of the citrate anion attracted $\mathrm{Ca}^{2+}$ cations more strongly than the other two. As sodium citrate resulted in the fastest dissolution of algae beads, it was used in the subsequent experiments.

\subsection{Quality and quantity assessment of recycled alginate}

The quantity of recovered alginate obtained from fresh beads (i.e. not used for wastewater treatment) indicates the efficiency of recycling and any possible losses. On average 17 algae beads can be produced from one millilitre of fresh alginate (VA) (Table 1). By comparison with the amount of algal beads produced from (non-supplemented) recovered alginate (11.7 beads $/ \mathrm{mL}$ ), a recovery rate of $69.1 \%$ can be calculated. A recovery rate of $77.1 \%$ was determined for empty beads. 
Table 1: Beads production from virgin and recycled alginate with and without algae.

\begin{tabular}{|l|c|c|c|}
\hline & \multicolumn{3}{|c|}{ Beads production [beads/mL alginate solution] } \\
\hline & Virgin alginate \pm SD & Recovered alginate \pm SD & Recovery rate \pm SD \\
\hline Empty beads $(n=14)$ & $17.7 \pm 2.7$ & $13.7 \pm 1.7$ & $77.1 \pm 8$ \\
\hline Algae beads $(n=6)$ & $17.1 \pm 1.6$ & $11.7 \pm 2.0$ & $69.1 \pm 15$ \\
\hline
\end{tabular}

SD: Standard deviation

The recovered alginate beads appeared to be a paler green colour compared to the beads made from fresh alginate, despite the same algal cell loading (Figure 3). The colour difference may have been caused by white calcium citrate residues reflecting the light (Supporting information, Figure S2). SEM images (Figure 4) showed that the surface structure looked similar for VA and RA beads and no recognizable difference could be seen between empty and algae beads (Figure 4a and 4b).

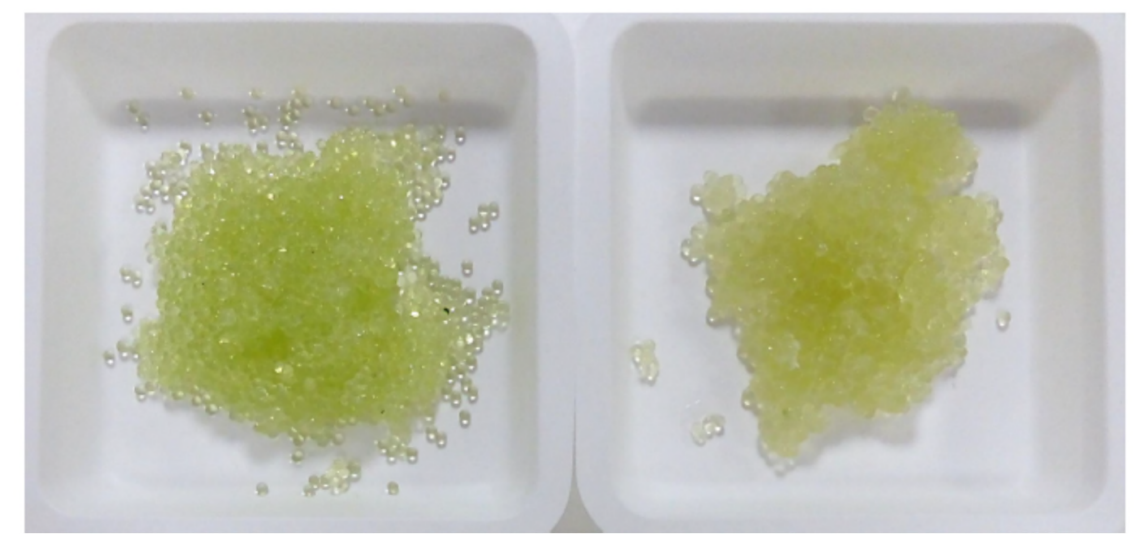

Figure 3: Photograph of VA (left) and RA beads (right).

As the beads were dissolved in Na-citrate there would have been some dilution of the original alginate concentration, which may influence the properties of the recycled alginate and thus the resultant product beads. This was assessed by viscosity and mechanical strength measurements. The viscosity can influence the gelation reaction and the size of the beads, whereas the strength of beads can be an indicator for the longevity of the beads when used in a fluidised bed reactor 
for wastewater treatment. The expected concentrations of RA solutions were calculated from the volume of sodium citrate and the weight of beads. The viscosity of three RA solutions was compared to a concentration series $(0.5 \%-2 \%)$ of VA in water and in Na-citrate (Table 2). For both VA solutions, viscosity increased with alginate concentration, but when dissolved in sodium citrate, this increase occurred at a slower rate. The RA had a markedly higher apparent viscosity; to illustrate, the viscosity of RA varied between 0.827 and $0.879 \mathrm{~Pa}$.s for concentrations of $1.17 \%$ and $1.23 \%$ compared to viscosities of 0.037 and 0.170 Pa.s for VA concentrations of 1 and $1.5 \%$, respectively, in Na-citrate. Accordingly, the RA exhibited a viscosity equivalent to a more concentrated VA (i.e., between 1.5 and 2\%). Despite the differences in the viscosities for VA and RA, beads could be formed from RA and functioned satisfactorily in a P removal trial run (section 3.3), clearly demonstrating that the change in viscosity had no impact on the bead production process.

Table 2: Viscosity in Pa.s at 7.6 /s of alginate solutions (in water and in Na-citrate) compared to recovered alginate solutions $(n=3$, Average $\pm S D$ ).

\begin{tabular}{|c|c|c|c|c|}
\hline & \multicolumn{3}{|c|}{ Viscosity of alginate solutions in Pa.s } \\
\hline $\begin{array}{c}\text { VA concentration } \\
{[\%]}\end{array}$ & VA in water & VA in Na-citrate & $\begin{array}{c}\text { RA concentration } \\
{[\%]}\end{array}$ & RA solution \\
\hline 0.5 & $0.027 \pm 0$ & $0.011 \pm 0$ & & \\
\hline 1 & $0.035 \pm 0.001$ & $0.037 \pm 0.001$ & 1.17 & $0.827 \pm 0.116$ \\
\hline 1.5 & $0.312 \pm 0.0002$ & $0.170 \pm 0.002$ & 1.2 & $0.848 \pm 0.174$ \\
\hline 2 & $1.021 \pm 0.026$ & $0.498 \pm 0.003$ & 1.23 & $0.879 \pm 0.064$ \\
\hline 2.5 & $1.856 \pm 0.019$ & $1.120 \pm 0.032$ & & \\
\hline
\end{tabular}




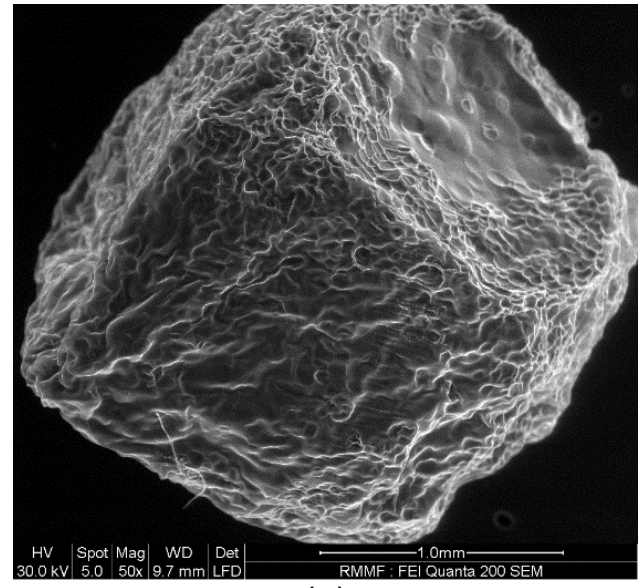

(a)

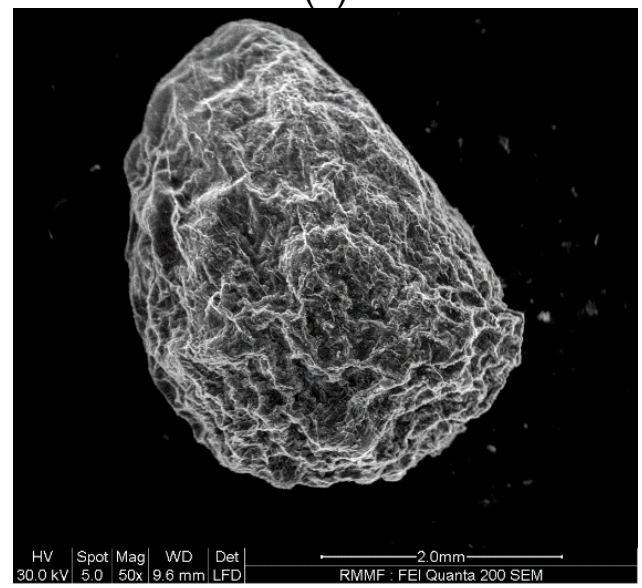

(c)

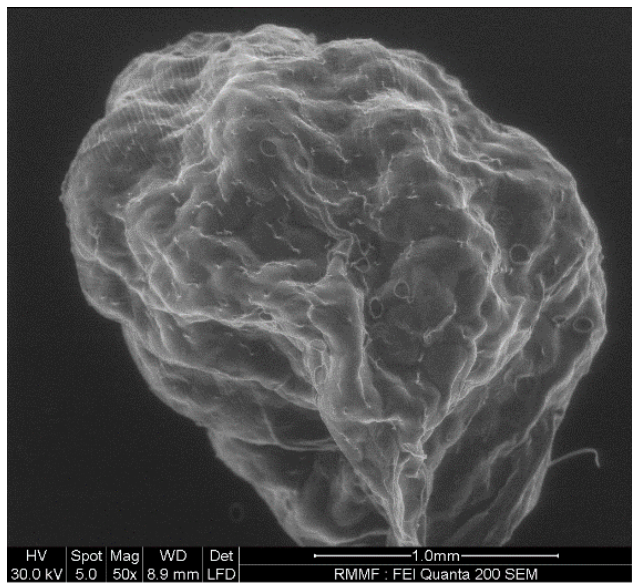

(b)

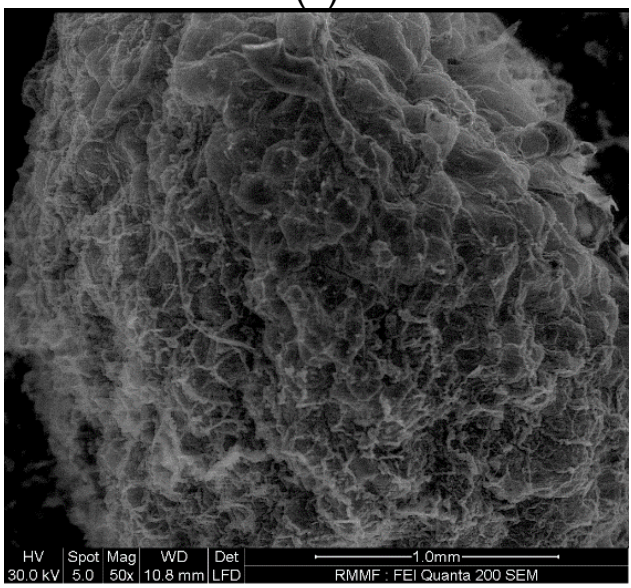

(d)

Figure 4: SEM images of (a) VA empty bead, (b) VA algae bead, (c) RA empty bead, (d) RA algae bead at $50 x$ magnification.

The compressibility of a set of VA and RA beads was measured to identify differences in their mechanical strength as this can indicate the life of beads when used in wastewater remediation. The force and strength to which beads resisted was recorded against compressive distance. Peak force and strength values were determined at those points where irreversible deformation of beads occurred (Table 3; Figure 5). No significant difference in the applied force was observed up to a compression of $0.5 \mathrm{~mm}$ beyond which the profiles differed significantly (Figure 5). The presence of algae cells within the beads did not seem to impact the mechanical strength profiles of beads in either VA or RA systems. The maximum force that beads withstood were $104.3 \mathrm{~g}$ and $100.9 \mathrm{~g}$ for empty and algae VA beads, respectively. In comparison, algae beads made from 
recovered alginate and supplemented with virgin alginate had a maximum force of $52.7 \mathrm{~g}$, which was about half that of the VA beads but markedly higher than for empty and algae RA beads. The peak strength values show a similar trend in a sequence of VA, RA supplemented with VA and RA alone (Table 3).

Table 3: Force and strength of beads ( $n=3$, Average \pm SD).

\begin{tabular}{|c|c|c|c|c|c|}
\hline & EB VA & AB VA & AB RA (supp) & EB RA & AB RA \\
\hline Peak force [g] & $104.3 \pm 64.7$ & $100.9 \pm 38.5$ & $52.7 \pm 3.4$ & $26.7 \pm 14.8$ & $25.5 \pm 19.5$ \\
\hline $\begin{array}{c}\text { Peak strength } \\
{[\mathrm{kg} / \mathrm{mm}]}\end{array}$ & $0.035 \pm 0.022$ & $0.034 \pm 0.013$ & $0.018 \pm 0.001$ & $0.009 \pm 0.005$ & $0.009 \pm 0.007$ \\
\hline
\end{tabular}

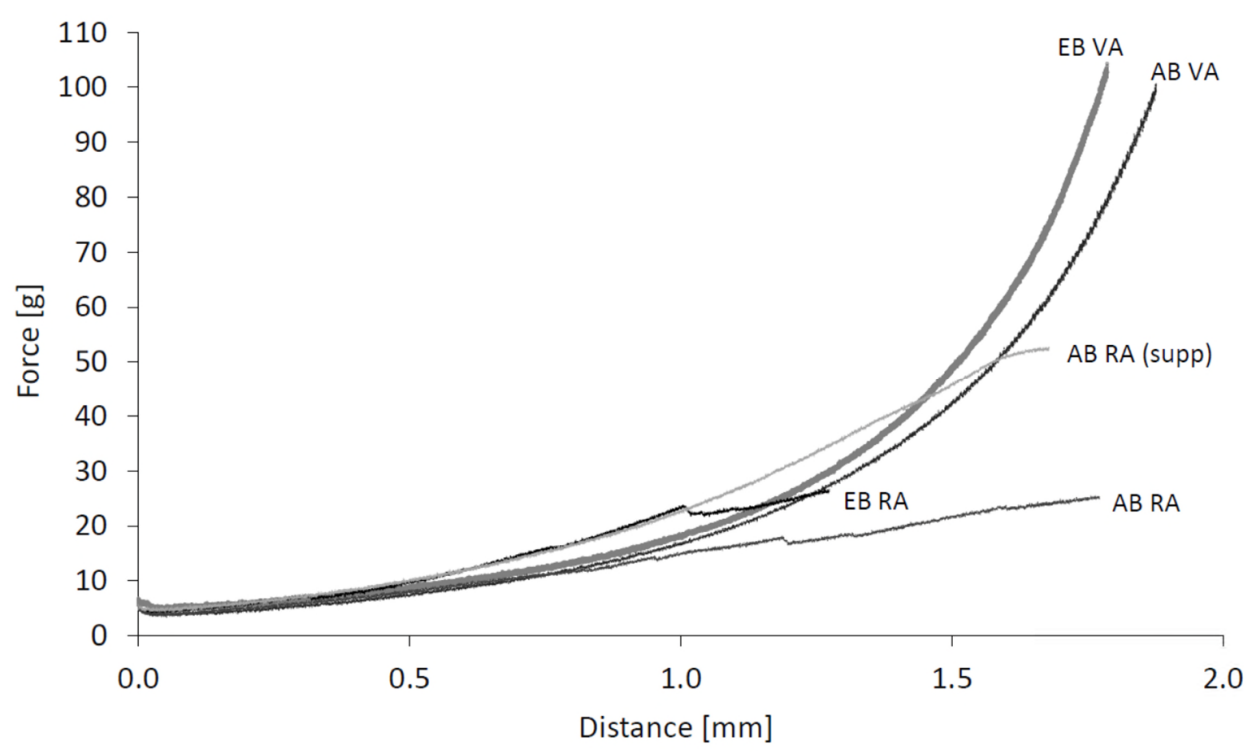

Figure 5:Compression profiles of EB: empty beads, $A B$ : algae beads, VA: virgin alginate and RA: recovered alginate, supp: supplemented with $1 \%$ alginate.

Overall, this indicates that recovered alginate has a higher viscosity but lower mechanical strength than VA. The mechanical strength can be partially enhanced by supplementing the recovered material with VA but the weaker beads may lead to a shorter beads' life. The current results are reinforced by comparison to medical trials with alginate fibres for wound dressings where calcium 
alginate showed swelling when dissolved and solidified again [13]. Both observations are congruent with a loosening of the egg-box structure due to additional citrate in the mixture causing a repelling effect and thus larger distances between polymer chains. The implication is that long term repeated recycling of the alginate may cause structural problems which need further investigation, and may require routine supplementation of a certain amount of fresh alginate.

\subsection{Impact on treatment efficiency}

To obtain a realistic representation of alginate recycling, fresh algae beads were used in a labscale photo-bioreactor trial which lasted 19 days. The alginate from the beads used in this experiment was then recycled to immobilise a second batch of algae. These beads were then used in parallel to a new batch of VA beads to compare their performance. The influent ortho-P concentration was on average $0.97 \mathrm{mg} \mathrm{P} / \mathrm{L}$ over the whole trial period. Trends were similar for algae in both VA and RA beads (Figure 6). From day 1 until 7, P concentrations decreased from 0.58 and $0.54 \mathrm{mg} \mathrm{P} / \mathrm{L}$ to 0.09 and $0.07 \mathrm{mg} \mathrm{P} / \mathrm{L}$ for $\mathrm{VA}$ and RA, respectively (Figure 6a), highlighting the potential of the technology to meet some of the stricter $\mathrm{P}$ consents of below 0.3 $\mathrm{mg} / \mathrm{L}$. In a previous study with a similar influent $\mathrm{P}$ concentration and at $20 \mathrm{~h} \mathrm{HRT}$, minimum effluent $P$ concentrations below $0.01 \mathrm{mg} / \mathrm{L}$ (below detection limit) were reported [5]. Between days 7 and 17 , effluent $P$ steadily increased to finally reach 1.31 and $0.9 \mathrm{mg} P / L$ for VA and RA, respectively. It is notable that the final concentrations were near or above the influent concentration on day 17 at which point the trial was stopped. The influent pH was on average 7.6. The $\mathrm{pH}$ increased with both VA and RA beads such that between days 1 and 8 , the $\mathrm{pH}$ varied between 7.6 and 8.5 for the VA beads before decreasing slowly to a final value of 7.0 on day 17 (Figure $6 \mathrm{~b}$ ). In the case of $\mathrm{RA}$, a maximum $\mathrm{pH}$ of 8.8 was reached on day 3 which then decreased slowly to the final $\mathrm{pH}$ of 7.5 . An elevated effluent $\mathrm{pH}$ has been shown to be partly caused by alkalinisation through uptake of $\mathrm{NO}_{3}-\mathrm{N}$ and a net decrease of $\mathrm{H}^{+}[5]$ as well as the algae growth on inorganic carbon [17]. Ammonia concentrations in the influent were $2.57 \mathrm{mg} \mathrm{NH}_{4}-\mathrm{N} / \mathrm{L}$ on 
average with concentrations as low as $1.24,0.1$ and $0.28 \mathrm{mg} \mathrm{NH}-\mathrm{N} / \mathrm{L}$ on days 3,13 and 17, respectively. Both VA and RA beads achieved very low ammonia concentrations consistently below $0.1 \mathrm{mg} \mathrm{NH}_{4}-\mathrm{N} / \mathrm{L}$, with VA having one spike of $1.99 \mathrm{mg} \mathrm{NH}_{4}-\mathrm{N} / \mathrm{L}$ on day 5 (Figure $6 \mathrm{~b}$ ). The variations in ammonia concentration observed in the influent are possibly due to the presence of nitrifying bacteria in the wastewater. This suggests that the very low ammonia levels observed in the effluent were achieved through a combined removal by the bacteria and the algae. The nitrate influent concentration was $2.39 \mathrm{mg} \mathrm{NO}-\mathrm{N} / \mathrm{L}$ on average with an unsteady trend overall. Again, the variation in the nitrate concentration in the feed support the suggestion that nitrifying bacteria are present in the wastewater. Both VA and RA beads resulted in effluent nitrate concentrations of $0.5 \mathrm{mg} \mathrm{NO}{ }_{3}-\mathrm{N} / \mathrm{L}$ and each having one peak on day 5 at 1.68 and $2.75 \mathrm{mg} \mathrm{NO}_{3}-\mathrm{N} / \mathrm{L}$ for $\mathrm{VA}$ and RA, respectively (Figure 6c). The ammonia and nitrate removal rates are comparable to previous studies with algae beads, where consistently low ammonia $(<0.001 \mathrm{mg} / \mathrm{L})$ and nitrate $(0.4 \mathrm{mg} / \mathrm{L})$ effluent concentrations were achieved with a $20 \mathrm{~h} \mathrm{HRT} \mathrm{and} \mathrm{similar} \mathrm{influent} \mathrm{concentrations} \mathrm{[5].} \mathrm{For}$ VA the algal cell concentrations rose rapidly to a plateau of $1.24-1.26 \times 10^{6}$ cells/bead between days 5 and 10 after which it decreased to $5.8 \times 10^{5}$ cells/bead on day 17 (Figure 6d). For RA, algae increased to a maximum of $1.53 \times 10^{6}$ cells/bead on day 8 and after that rapidly decreased to a final concentration of $3.5 \times 10^{5}$ cells/bead.

These parallel trials of VA and RA beads showed similar results suggesting that recycling of alginate is possible for use in wastewater remediation without an apparent negative impact on performance. However, the period over which low $P$ levels $(<0.5 \mathrm{mg} / \mathrm{L})$ were achieved (up to day 7) was notably shorter in comparison to the previously reported studies where low levels were maintained until up to 20 days [5]. As this difference was observed for both VA and RA beads, it cannot be attributed to an impact of the alginate recycling process on beads' life but can possibly be explained by variations in the wastewater composition with for example a significant difference in nitrate concentration. As the cells concentrations within the beads were also found to significantly decrease from the 7-day point, these results also show that the system was affected 
by possibly beads degradation leading to a release of algae cells and/or by direct impact on the cells metabolism. However, this highlights a general variation in beads' life depending on the conditions which could have a direct impact on the savings to be made especially when considering the supplementation of the beads with fresh alginate. 


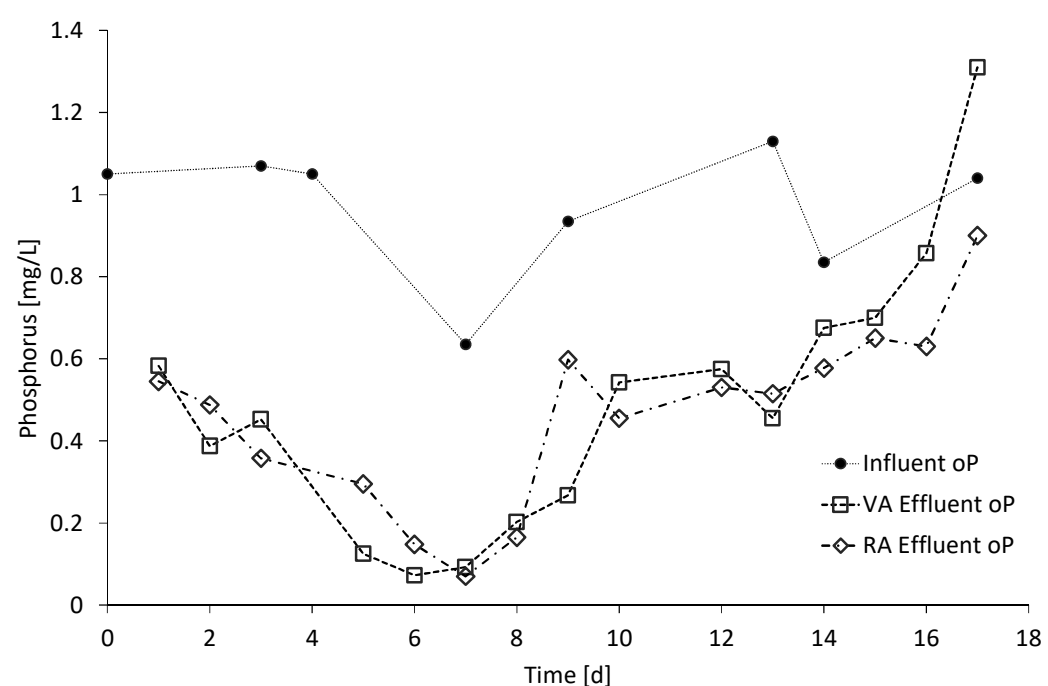

(a)

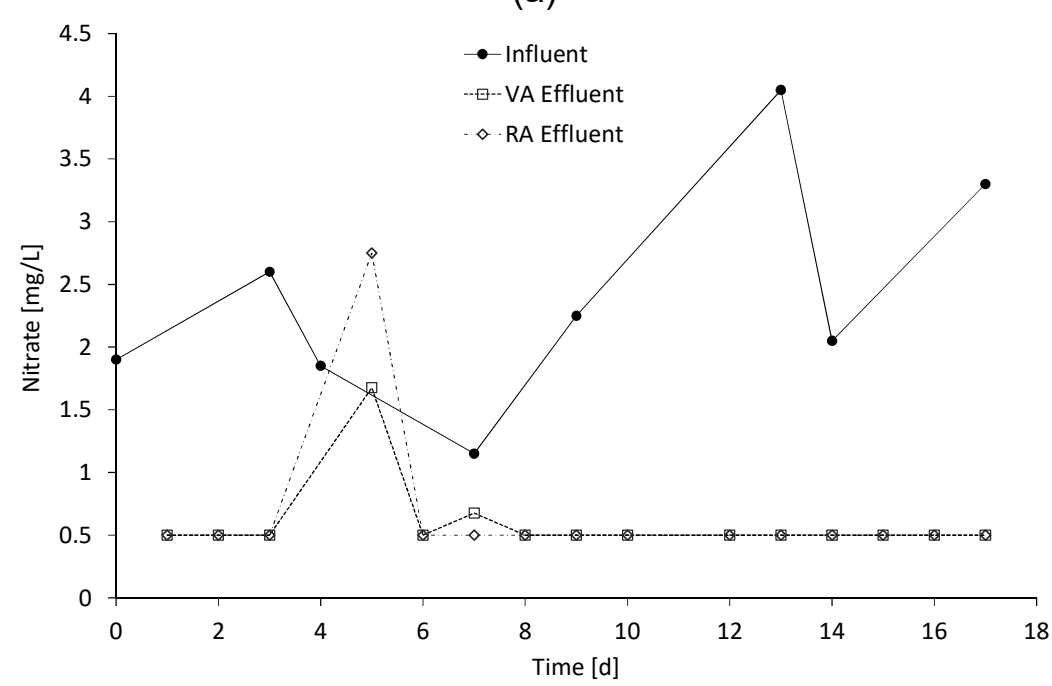

(c)

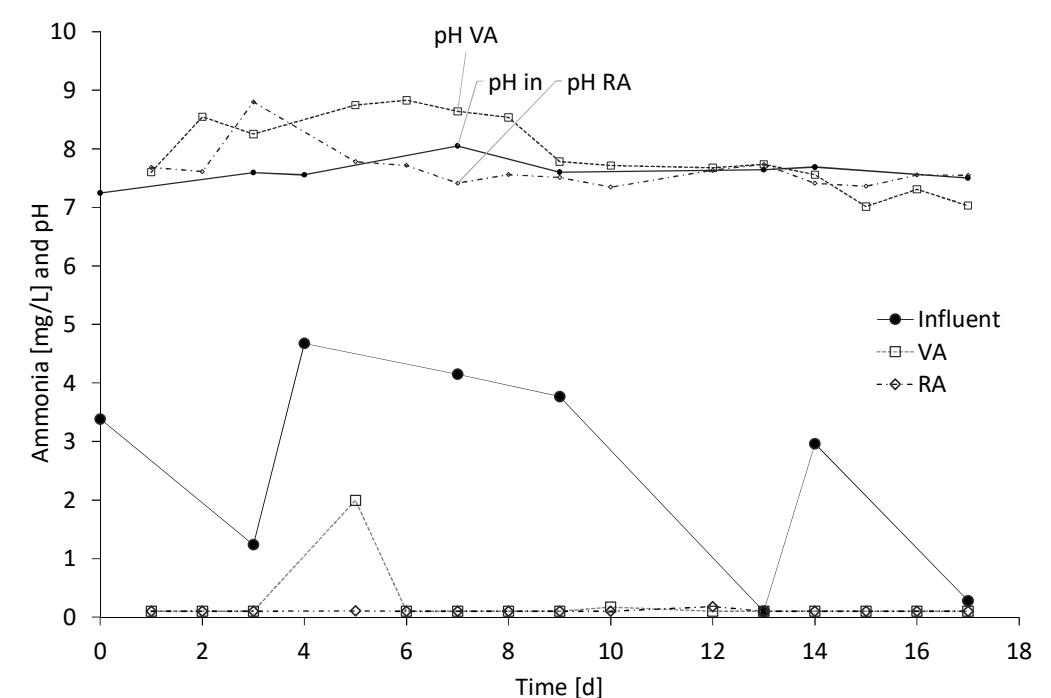

(b)

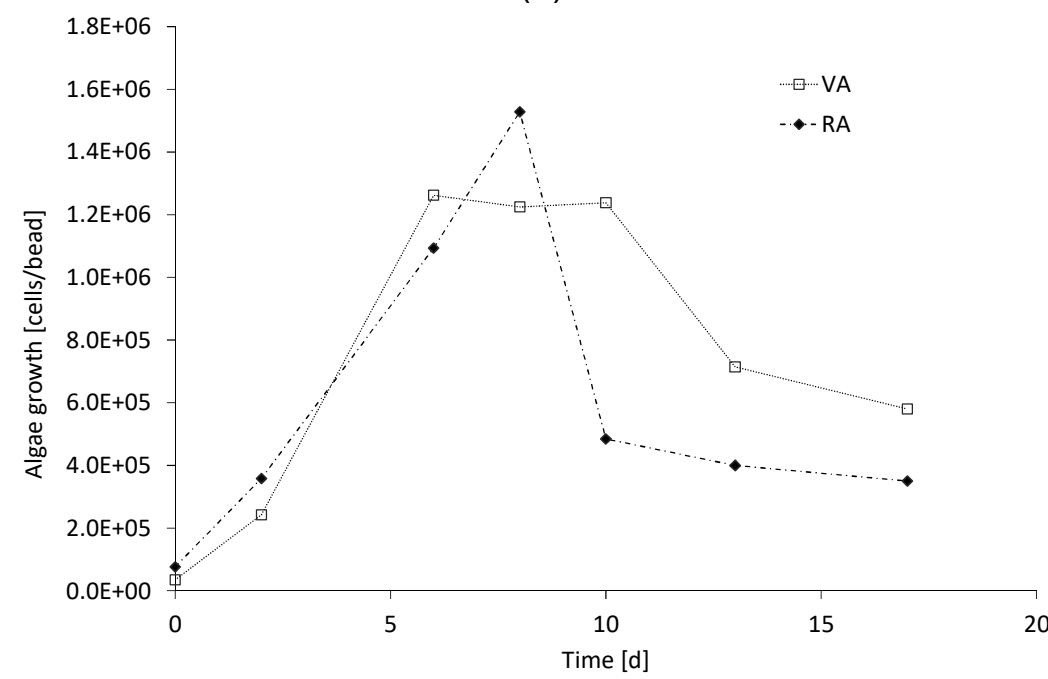

(d)

Figure 6: Performance of VA and RA algal beads in continuous photo-bioreactors. Influent $(\bullet)$, VA effluent $(\square)$, RA effluent $(\diamond)$ for $(a)$ P concentration (b) $\mathrm{NH}_{4}-\mathrm{N}$ and $\mathrm{pH}$ (c) $\mathrm{NO}_{3}-\mathrm{N}$ (d) algae cell concentration. 


\subsection{Economic assessment for alginate recovery}

The results obtained in this work were used to evaluate the economic impact of alginate recycling on IBR operation for 1 year at a wastewater treatment plant of $1000 \mathrm{PE}$. Only the costs for bead making, dissolution and re-immobilisation were considered as part of the net operational expenditure (nOPEX) and the costs for $\mathrm{CaCl}_{2}$ and machinery for bead making were not considered here as they will be the same in both scenarios (Table 4). The comparison considered a scenario with and without alginate recovery. A sensitivity analysis was undertaken where bead life, virgin alginate costs and recovery rates were varied $(+/-50 \%$ of original value) and their respective impact on nOPEX was studied.

Table 4: Parameters used in economic analysis.

\begin{tabular}{|c|c|c|c|}
\hline Parameter & & Unit & Sensitivity \\
\hline Cost of sodium alginate & 33.04 & $\mathrm{f} / \mathrm{kg}$ & \multirow{3}{*}{$+/-50 \%$} \\
\hline Bead life/Batch duration & 20 & Days & \\
\hline Recovery rate for alginate & 60 & $\%$ & \\
\hline Cost of trisodium citrate & 0.924 & $\mathrm{f} / \mathrm{kg}$ & \multirow{4}{*}{ Fixed values } \\
\hline Production of algae beads & 17 & Beads/ mL alginate & \\
\hline Flow rate (1000 PE) & 180 & $\mathrm{~m}^{3} / \mathrm{d}$ & \\
\hline HRT (IBR) & 24 & $\mathrm{~h}$ & \\
\hline
\end{tabular}

When all parameters (Table 4) are fixed, nOPEX can be reduced by $50 \%$ when recovery of alginate is implemented. Beads' lives of 20 days have commonly been reported in the literature [5], hence have been assumed for this assessment. For variations of beads' life (the duration of one batch) between 10 and 30 days, the same reduction in nOPEX of $50 \%$ will apply when recovering alginate. Although increasing bead life, and thus decreasing number of annual batches, will reduce overall operational costs, this effect will be at the same rate in both scenarios, whether with or without recovery.

The cost for sodium alginate is likely to vary depending on its origin/source [18] and with current research developments for alginate, like polymer recovery from granular sludge, the costs may 
decrease in the future $[14,19]$. Cost variations of sodium alginate between $£ 16.52$ and $£ 49.55$ per kilogram will first impact the whole IBR process even without alginate recovery. With a $60 \%$ alginate recovery rate, nOPEX will be reduced between $39 \%$ and $53 \%$ for the lowest and highest alginate costs, respectively (Figure 7).

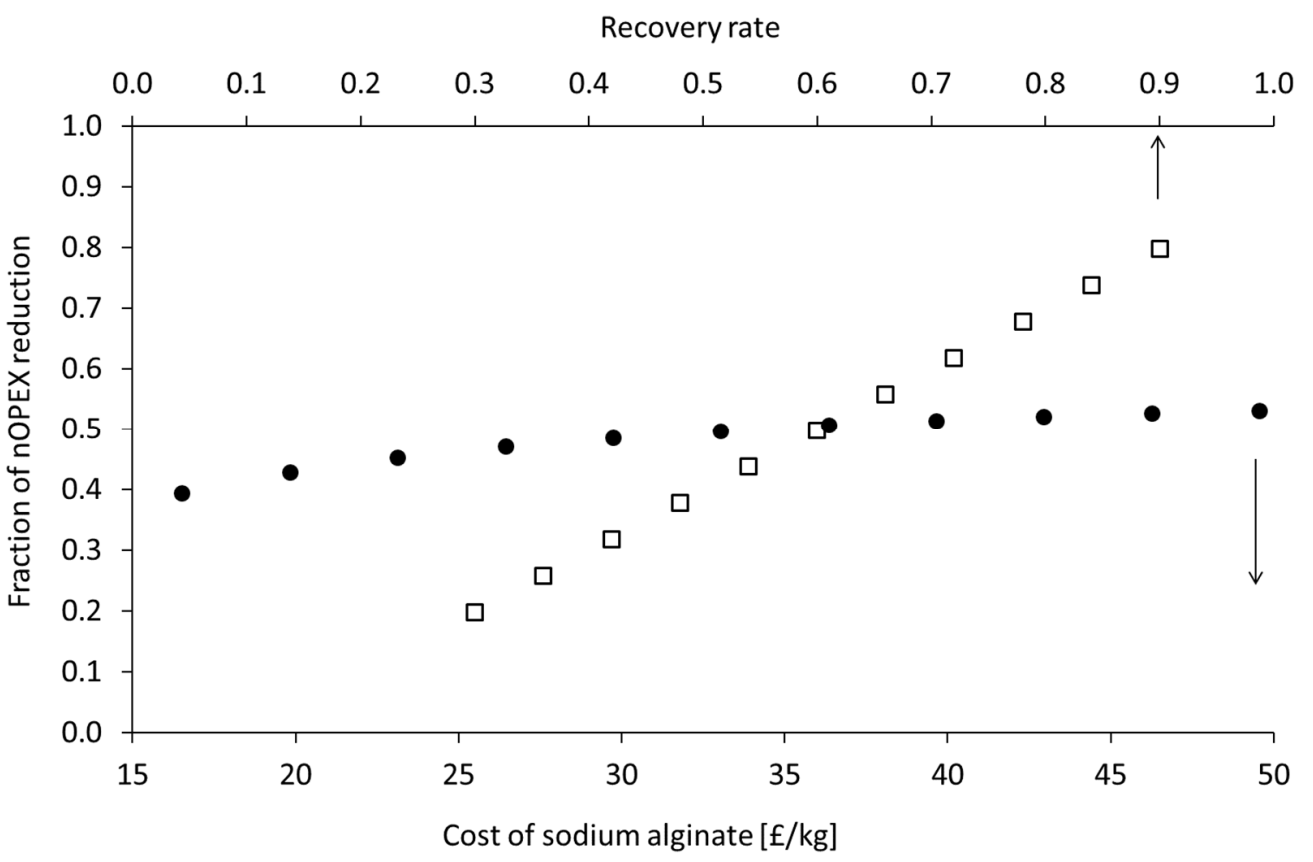

Figure 7: Development of nOPEX cost reduction with variation of sodium alginate costs $(\bullet)$ and recovery rate $(\square)$.

There is also a breakeven alginate cost of $£ 4.75 / \mathrm{kg}$ below which a system without alginate recovery may be more economically beneficial than with recovery. This decrease in alginate cost may occur with the onset of the use of wastewater derived alginate like polymers. Therefore, it is realistic to assume that in the future the IBR process may become economically viable even without alginate recovery. Changes of the recovery rate of alginate will have the biggest impact on nOPEX. At a recovery rate of $30 \%$ the costs can be reduced by $20 \%$, however if it were possible to increase the recovery rate to $90 \%$, nOPEX could be reduced by $80 \%$. As opposed to 
projected alginate costs, which are subject to uncertainty, the recovery rate can be controlled to a certain point by improving the operational conditions. Therefore, it appears that an improved alginate recovery method will be most valuable for the advancement of the IBR process towards full-scale applications.

\section{Conclusions}

The objective of this work was to give a proof-of-concept of the recycling of alginate in an immobilised algae system. The results showed that recycled alginate from algae beads at a recovery rate of approximately $70 \%$ can be obtained. Although RA beads showed a lower mechanical strength than VA beads, both achieved similar treatment efficiency. At current costs of chemicals, recovery of alginate can bring a $60 \%$ net operational cost reduction. This can be increased with further improvements in recovery, such as further optimisation of the required concentration of the dissolving agent (in this case sodium citrate) to reduce costs and dilution rates. It will also be economically beneficial to determine the minimum amount of sodium alginate supplementation needed for sufficient bead strength and nutrient removal performance in wastewater treatment. This work has shown that alginate recovery in an IBR system can provide significant economic benefit without loss in wastewater treatment performance and it therefore contributed to move development towards full-scale applications.

\section{Acknowledgements}

Funding for this study was gratefully received by Severn Trent Water and the Royal Society of Chemistry Water Science group in form of the Alan Tetlow Memorial Bursary. The authors gratefully acknowledge the facilities, and the scientific and technical assistance, of the Australian Microscopy \& Microanalysis Research Facility at the RMIT Microscopy \& Microanalysis Facility, the facilities and technical support by Nadia Zakhartchouk at the Separation Science and Mass 
Spectrometry Facility, the facilities and the technical support by Muthu Pannirselvam at the Rheology and Materials Characterisation Laboratory and finally the facilities of the Food Research and Innovation Centre at RMIT University.

\section{References}

[1] Infante C, Leon I, Florez J, Zarate A, Barrios F, and Zapata C. Removal of ammonium and phosphate ions from wastewater samples by immobilized Chlorella sp. Int. J. Environ. Studies. 2013; 70(1): 1-7.

[2] Liu K, Li J, Qiao H, Lin A, and Wang G. Immobilization of Chlorella sorokiniana GXNN 01 in alginate for removal of $\mathrm{N}$ and $\mathrm{P}$ from synthetic wastewater. Bioresour. Technol. 2012; 114: $26-$ 32.

[3] Whitton R, Ometto F, Pidou M, Jarvis P, Villa R, and Jefferson B. Microalgae for municipal wastewater nutrient remediation: mechanisms, reactors and outlook for tertiary treatment. Environ. Technol. Rev. 2015; 4(1): 133-148.

[4] De-Bashan LE, and Bashan Y. Recent advances in removing phosphorus from wastewater and its future use as fertilizer (1997-2003). Water Res. 2004; 38(19): 4222-4246.

[5] Whitton R, Santinelli M, Pidou M, Ometto F, Henderson R, Roddick F, Jarvis P, Villa R, and Jefferson B. Tertiary nutrient removal from wastewater by immobilised microalgae: impact of wastewater nutrient characteristics and hydraulic retention time (HRT). H2Open J. 2018; 1(1): $12-25$.

[6] Ometto F, Quiroga G, Psenicka P, Whitton R, Jefferson B, and Villa R. Impacts of microalgae pre-treatments for improved anaerobic digestion: thermal treatment, thermal hydrolysis, ultrasound and enzymatic hydrolysis. Water res. 2014; 65: 350-61. 
[7] Ometto F, Whitton R, Coulon F, Jefferson B, and Villa R. Improving the energy balance of an integrated microalgal wastewater treatment process. Waste Biomass Valorization. 2013; $5(2)$ : $245-253$.

[8] Whitton R, Le Mevel A, Pidou M, Ometto F, Villa R, and Jefferson B. Influence of microalgal N and P composition on wastewater nutrient remediation. Water Res. 2016; 91: 371-378.

[9] Ching SH, Bansal N, and Bhandari B. Alginate gel particles-A review of production techniques and physical properties. Crit. Rev. Food Sci. Nutr. 2017; 57(6): 1133-1152.

[10] Whitton RL. Algae Reactors for Wastewater Treatment. Ph.D. diss., Cranfield University, 2016.

[11] Velings NM, and Mestdagh MM. Physico-chemical properties of alginate gel beads. Polym. Gels Netw. 1995; 3(3): 311-330.

[12] Bajpai SK, and Sharma S. Investigation of swelling/degradation behaviour of alginate beads crosslinked with $\mathrm{Ca}^{2+}$ and $\mathrm{Ba}^{2+}$ ions. React. Funct. Polym. 2004; 59(2): 129-140.

[13] Qin $\mathrm{Y}, \mathrm{Hu} \mathrm{H}$, and Luo A. The conversion of calcium alginate fibers into alginic acid fibers and sodium alginate fibres. J. Appl. Polym. Sci. 2006, 101(6): 4216-4221.

[14] Van Der Hoek JP, De Fooij H, and Struker A. Wastewater as a resource: Strategies to recover resources from Amsterdam's wastewater. Resour. Conserv. and Recy. 2016; 113: 53-64.

[15] Abdel Hameed MS. Effect of algal density in bead, bead size and bead concentration on wastewater nutrient removal. Afr. J. Biotechnol. 2007; 6(10): 1185-1191.

[16] Gebauer D, Volkel A, and Colfen H. Stable prenucleation calcium carbonate clusters. Science. 2008; 322(5909): 1819-1823.

[17] Sutherland DL, Howard-Williams C, Turnbull MH, Broady PA, and Craggs RJ. The effects of $\mathrm{CO} 2$ addition along a $\mathrm{pH}$ gradient on wastewater microalgal photo-physiology, biomass production and nutrient removal. Water Res. 2015; 70: 9-26 
113 [18] Kube M, Mohseni A, Fan L, and Roddick F. Impact of alginate selection for wastewater 114 treatment by immobilised Chlorella vulgaris. Chem. Eng. J. 2019; 358: 1601-1609.

115 [19] Lin Y, de Kreuk M, van Loosdrecht MC, and Adin A. Characterization of alginate-like 116 exopolysaccharides isolated from aerobic granular sludge in pilot-plant. Water Res. 2010; 44(11): $117 \quad 3355-3364$. 


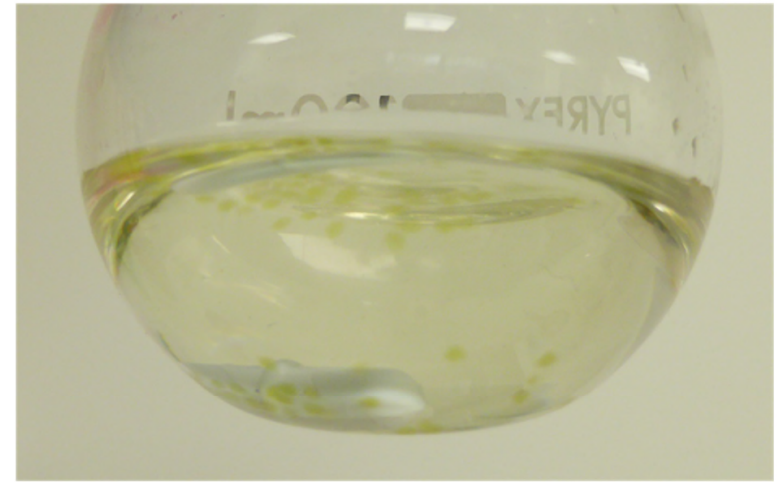

Na-citrate $10 \mathrm{~min}$

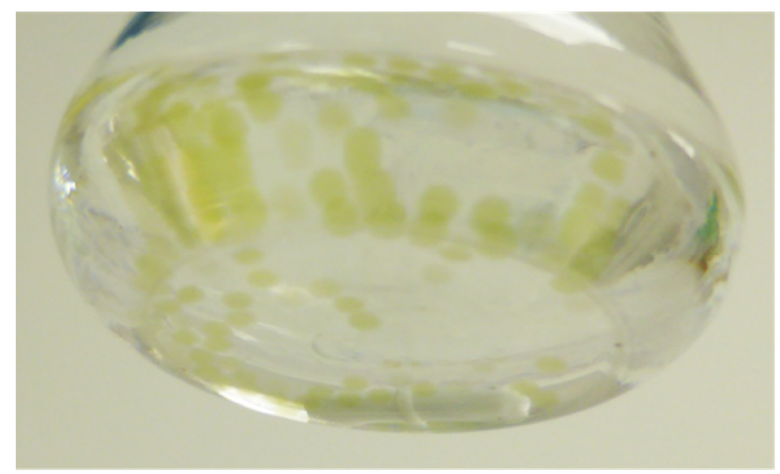

$\mathrm{NaCl} 30 \mathrm{~min}$

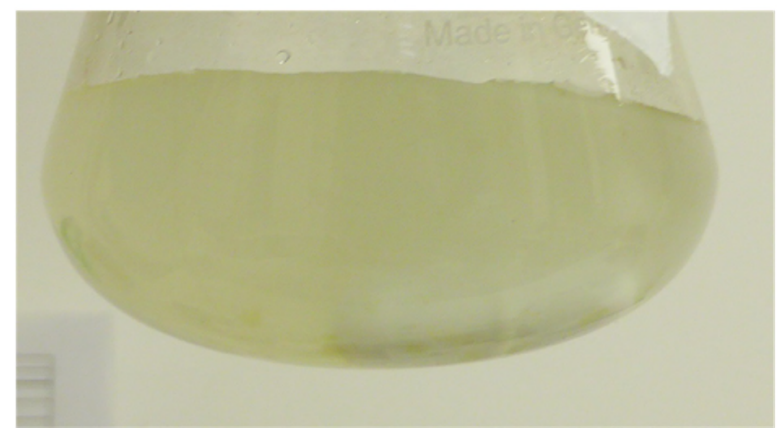

$\mathrm{Na}_{2} \mathrm{CO}_{3} 30 \mathrm{~min}$

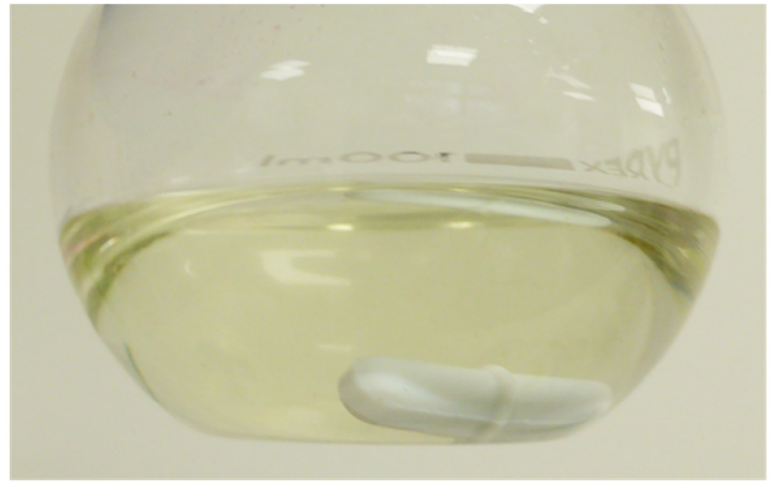

Na-citrate $20 \mathrm{~min}$

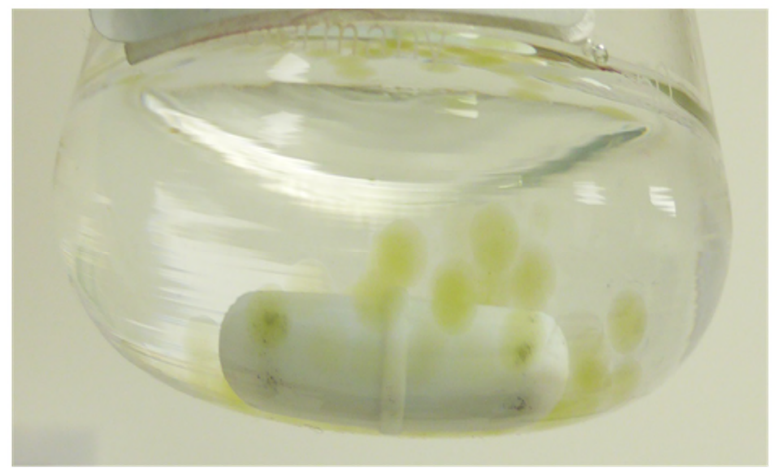

$\mathrm{NaCl} 150 \min$

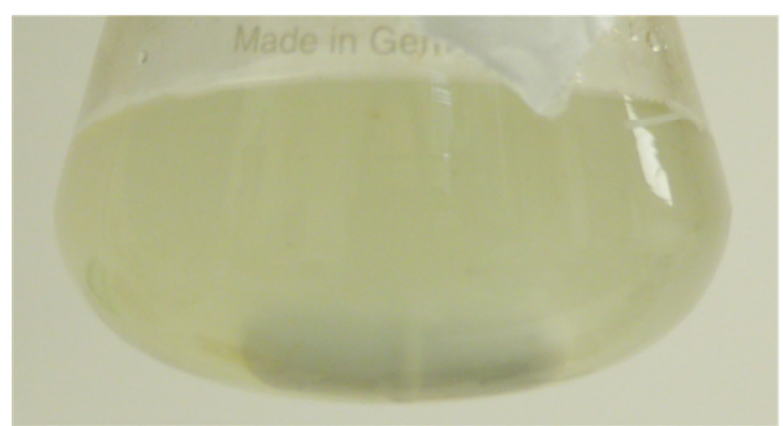

$\mathrm{Na}_{2} \mathrm{CO}_{3} 40 \mathrm{~min}$

Figure S.1. Algae beads in respective dissolution solutions. 


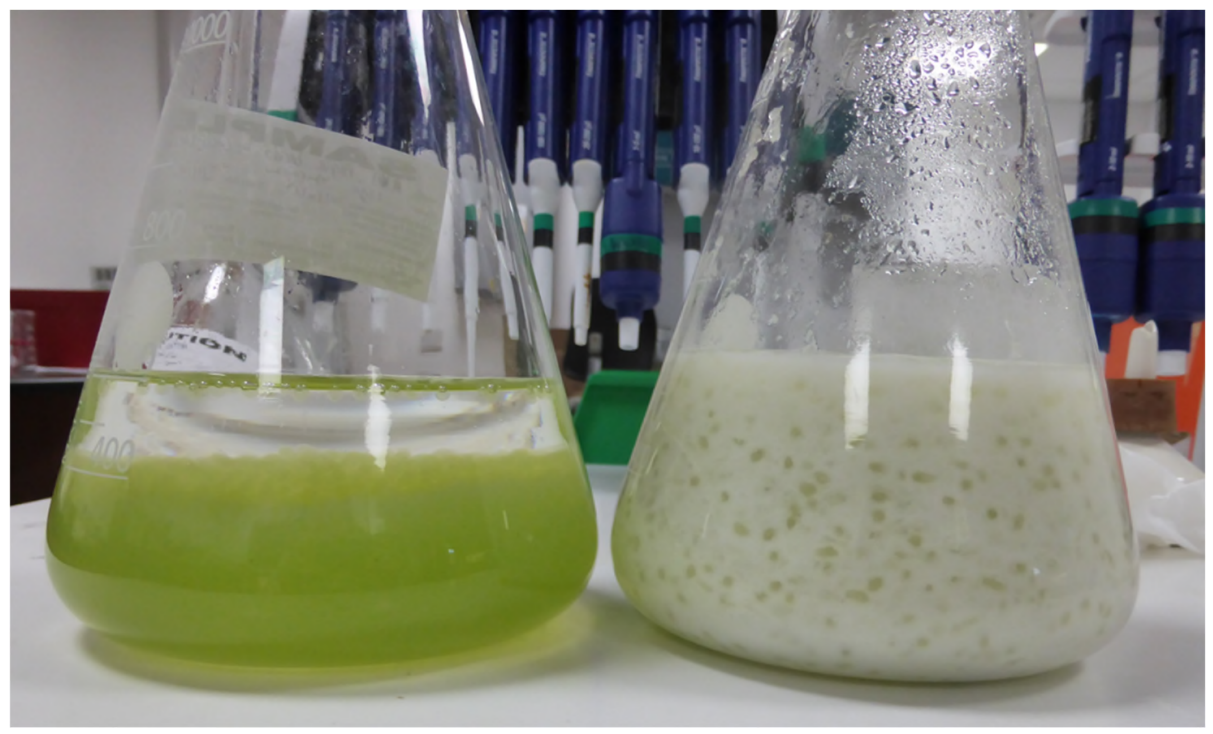

Figure S.2. Algae beads made from VA (left) and RA (right) after stirring. 